\title{
Technical Note: Methionine, a precursor of methane in living plants
}

\author{
K. Lenhart ${ }^{1,2,3}$, F. Althoff ${ }^{1,2}$, M. Greule ${ }^{1,2}$, and F. Keppler ${ }^{1,2}$ \\ ${ }^{1}$ Max Planck Institute for Chemistry, Hahn-Meitner-Weg 1, 55128 Mainz, Germany \\ ${ }^{2}$ Institute of Earth Sciences, University Heidelberg, Im Neuenheimer Feld 234-236, 69120 Heidelberg, Germany \\ ${ }^{3}$ Department of Plant Ecology (IFZ), Heinrich-Buff-Ring 26-32, 35320 Gießen, Germany
}

Correspondence to: K. Lenhart (katharina.lenhart@mpic.de) and F. Keppler (frank.keppler@mpic.de)

Received: 8 July 2014 - Published in Biogeosciences Discuss.: 26 November 2014

Revised: 10 February 2015 - Accepted: 3 March 2015 - Published: 23 March 2015

\begin{abstract}
When terrestrial plants were identified as producers of the greenhouse gas methane, much discussion and debate ensued not only about their contribution to the global methane budget but also with regard to the validity of the observation itself. Although the phenomenon has now become more accepted for both living and dead plants, the mechanism of methane formation in living plants remains to be elucidated and its precursor compounds to be identified. We made use of stable isotope techniques to verify the in vivo formation of methane, and, in order to identify the carbon precursor, ${ }^{13} \mathrm{C}$ positionally labeled organic compounds were employed. Here we show that the amino acid L-methionine acts as a methane precursor in living plants. Employing ${ }^{13} \mathrm{C}$ labeled methionine clearly identified the sulfur-bound methyl group of methionine as a carbon precursor of methane released from lavender (Lavandula angustifolia). Furthermore, when lavender plants were stressed physically, methane release rates and the stable carbon isotope values of the emitted methane greatly increased. Our results provide additional support that plants possess a mechanism for methane production and suggest that methionine might play an important role in the formation of methane in living plants, particularly under stress conditions.
\end{abstract}

\section{Introduction}

The observation that plants produce methane $\left(\mathrm{CH}_{4}\right)$ under aerobic conditions has caused considerable controversy in the scientific community (Keppler et al., 2006; Dueck et al., 2007; Evans, 2007; Beerling et al., 2008; Kirschbaum and Walcroft, 2008; McLeod et al., 2008; Vigano et al., 2008; Wang et al., 2008; Nisbet et al., 2009; Bloom et al., 2010;
Covey et al., 2012; Zhang et al., 2014). Despite much scepticism, a number of recent studies provide support for the phenomenon not only for living plants but also for dead plant matter (Keppler et al., 2009; Qaderi and Reid, 2011; Bruhn et al., 2012; Wang et al., 2013).

Nonmicrobial $\mathrm{CH}_{4}$ release has been shown to occur from dry and detached fresh plant material under ultraviolet (UV) irradiation and elevated temperatures (McLeod et al., 2008; Vigano et al., 2008; Bruhn et al., 2009). Pectin has been considered a source of $\mathrm{CH}_{4}$ production, primarily because of its high degree of methylation (Keppler et al., 2008; Bruhn et al., 2009; Messenger et al., 2009). A reaction of reactive oxygen species (ROS) with pectic polysaccharides was suggested as a possible route to $\mathrm{CH}_{4}$ formation under UV radiation (Messenger et al., 2009). From plant matter, $\mathrm{CH}_{4}$ can be derived from other structural components, as shown with commercially purified lignin and cellulose (Vigano et al., 2008), leaf surface waxes (Bruhn et al., 2014), and even with ascorbic acid under highly oxidative conditions (Althoff et al., 2010). For further information on $\mathrm{CH}_{4}$ formation from dry and fresh detached plant matter and specific plant structural compounds, the reader should refer to the recent reviews of Bruhn et al. (2012) and Wang et al. (2013).

Stable isotope analysis has been employed to demonstrate that living plants release $\mathrm{CH}_{4}$ at rates ranging from 0.16 to $12 \mathrm{ng} \mathrm{g}^{-1}$ dry weight (DW) $\mathrm{h}^{-1}$ (Brüggemann et al., 2009; Wishkerman et al., 2011). Isotope labeling studies involving young poplars grown in a ${ }^{13} \mathrm{CO}_{2}$ atmosphere (Brüggemann et al., 2009) together with several plants cell culture experiments with ${ }^{13} \mathrm{C}$-labeled sucrose (Wishkerman et al., 2011) confirmed that $\mathrm{CH}_{4}$ is produced in plants per se and not by their associated microorganisms. Here it was suggested that $\mathrm{CH}_{4}$ formation was the result of abiotic stress factors to 
which the plant had been exposed, an idea supported by the findings of two other recent studies (Qaderi and Reid, 2009, 2011). Although these results would support the contention that living plants release $\mathrm{CH}_{4}$, the mechanism of its formation and its precursors still remain unknown.

A first step towards delineating the formation pathway was recently undertaken by Wishkerman et al. (2011), who investigated the influence of the toxin sodium azide $\left(\mathrm{NaN}_{3}\right)$ on cell cultures such as tobacco, sugar beet and grape vine. As sodium azide is known to disrupt electron transport flow at the cytochrome c oxidase (complex IV) in plant mitochondria, the findings of the study suggested that a disturbance in the electron transport chain (ETC) causes $\mathrm{CH}_{4}$ formation in plant cells. Thus, $\mathrm{CH}_{4}$ formation in living plants may be an integral part of cellular responses to changes in oxidative status present in all eukaryotes. It has been hypothesized that compounds such as phosphatidylcholine or methionine (Met) might be carbon precursors of $\mathrm{CH}_{4}$ in both animal and plant cells, particularly when under stress conditions (Wishkerman et al., 2011; Bruhn et al., 2012)

Furthermore, very recently a chemical reaction showing that $\mathrm{CH}_{4}$ can be readily formed from organosulfur compounds under oxidative conditions, ambient atmospheric pressure and temperature has been suggested (Althoff et al., 2014). In the first step of the reaction, methyl sulfides are oxidized to the corresponding sulfoxides. Then, in the next step, demethylation of the sulfoxide via homolytic bond cleavage leads to methyl radical formation and finally to $\mathrm{CH}_{4}$. In the same study, tobacco plants (Nicotiana tabacum) grown under sterile conditions were supplemented with positionally labeled Met, where only the methyl group $\left(-\mathrm{S}-\mathrm{CH}_{3}\right)$ was enriched with ${ }^{13} \mathrm{C}$ atoms. These experiments provided the first pieces of evidence that the thiomethyl group of Met is a parent compound of $\mathrm{CH}_{4}$ in tobacco plants. The potential role of methionine and its oxidation product methionine sulfoxide (MSO) in $\mathrm{CH}_{4}$ biosynthesis in living plants was also suggested by Bruhn et al. (2012). Additionally, methionine has been shown to be involved in $\mathrm{CH}_{4}$ formation in saprotrophic fungi (Lenhart et al., 2012).

In this study we investigated methionine, an amino acid that plays a major role in transmethylation reactions, as a precursor of $\mathrm{CH}_{4}$ biosynthesis in living plants under dark conditions. We employed Lavandula angustifolia, which was previously shown to produce significant amounts of $\mathrm{CH}_{4}$ both under normal and stress conditions, such as physical wounding and anoxia (Wang et al., 2009, 2011a, b). We made use of stable isotope techniques and ${ }^{13} \mathrm{C}$ positionally labeled methionine to verify in vivo formation and identify the carbon atom precursor of $\mathrm{CH}_{4}$.

\section{Material and methods}

\subsection{Cultivation of plants}

Commercially available $L$. angustifolia plants grown to approximately $20-25 \mathrm{~cm}$ were purchased for the initial experiment (consecutive treatment experiment). Plants used in the second experiment (parallel treatment experiment) were grown in a greenhouse until a height of $20 \mathrm{~cm}$ was reached. Trace gas measurements were carried out at $22 \pm 2{ }^{\circ} \mathrm{C}$ and $100 \%$ humidity under dark conditions.

\subsection{Supplementation of $L$. angustifolia with ${ }^{13}$ C-methionine}

L. angustifolia plants were removed from pots and the soil washed from the roots. For incubation, each plant was placed inside a $2.5 \mathrm{~L}$ flask (Weck ${ }^{\oplus}$, Hanau, Germany) containing $50 \mathrm{~mL}$ distilled $\mathrm{H}_{2} \mathrm{O}$ and then sealed with a lid held in place with a rubber band. To facilitate headspace sampling each lid had a central hole fitted with a silicone stopper. In the ${ }^{13} \mathrm{C}$ Met labeled flasks, the distilled water was supplemented with $0.4 \mathrm{mM}{ }^{13} \mathrm{C}$-Met. We used a positionally labeled Met where only the methyl group $\left(-\mathrm{S}-\mathrm{CH}_{3}\right)$ was enriched with ${ }^{13} \mathrm{C}$ atoms. After sealing, measurements of headspace $\mathrm{CH}_{4}$ concentrations and ${ }^{13} \mathrm{C}_{-} \mathrm{CH}_{4}$ signatures were conducted over a 4-day period. Different incubation periods and measurement intervals were necessary to correspond with the available schedule times for using the isotope measurement system. For isotope measurements the incubation flask was directly connected to the isotope ratio mass spectrometry (IRMS) system.

\subsection{Physical stressing of plants}

Detached leaves of $L$. angustifolia have previously been shown to release significant amounts of $\mathrm{CH}_{4}$ both under normal and stress conditions, such as physical wounding by cutting (Wang et al., 2011b). However, stressing of plants by cutting is a time-consuming process and a rapid, stressinduced increase in $\mathrm{CH}_{4}$ emissions might occur during this process and before the flasks were sealed. Therefore, physical stress in our study was performed by gently compressing individual leaves of each plant between fingertips for a short time period $(1-2 \mathrm{~s})$. This procedure took approximately $1 \mathrm{~min}$ for each plant, i.e. until the majority of the leaf surface area was injured.

\subsection{Analytical procedures}

Gas samples were analyzed within $24 \mathrm{~h}$ in a gas chromatograph (Shimadzu GC-14B, Kyoto, Japan) with a flame ionization detector $\left(\mathrm{CH}_{4}\right)$ and an electron capture detector $\left(\mathrm{N}_{2} \mathrm{O}\right.$, $\mathrm{CO}_{2}$ ) operated at 230 and $320^{\circ} \mathrm{C}$ with $\mathrm{N}_{2}$ as carrier gas $\left(25 \mathrm{~mL} \mathrm{~min}^{-1}\right.$ ) (Kammann et al., 2009, 2012). The GC column (PorapakQ, Millipore, Schwallbach, mesh 80/100) was 
Table 1. Rates of formation and $\delta^{13} \mathrm{C}$ signature increase in $\mathrm{CH}_{4}$ released during incubation of L. angustifolia plants before and after physical stress. Samples 1-5 were measured in experiment 1 (consecutive treatment experiment, measurements at day 1 , non-stressed, and day 2 , stressed) and samples 6-14 in experiment 2 (parallel treatment experiment). The difference in the $\mathrm{CH}_{4}$ rate increase between the non-stressed and stressed treatments was significant ( $p=0.003$ and $p=0.005$ for experiments 1 and 2 , respectively).

\begin{tabular}{|c|c|c|c|c|c|c|}
\hline \multirow[t]{2}{*}{ Sample } & \multicolumn{3}{|c|}{$\mathrm{CH}_{4}\left(\mathrm{ng} \mathrm{g}^{-1} \mathrm{~h}^{-1}\right)$} & \multicolumn{3}{|c|}{$\Delta^{13} \mathrm{CH}_{4}\left(\% \circ \mathrm{g}^{-1} \mathrm{~h}^{-1}\right)$} \\
\hline & Non-stressed & Stressed & Ratio stressed / non-stressed & Non-stressed & Stressed & Ratio stressed / non-stressed \\
\hline 1 & 0.52 & 1.70 & 3.3 & - & - & \\
\hline 2 & 0.57 & 1.87 & 3.3 & - & - & \\
\hline 3 & 0.43 & 2.41 & 5.6 & - & - & \\
\hline $4 *$ & 0.31 & 1.21 & 3.9 & 0.27 & 0.39 & 1.4 \\
\hline $5^{*}$ & 0.18 & 1.67 & 9.1 & 0.11 & 0.34 & 3.2 \\
\hline 6 & 0.37 & - & & - & - & \\
\hline 7 & 0.39 & - & & - & - & \\
\hline 8 & 0.14 & - & & - & - & \\
\hline $9 *$ & 0.24 & - & & 0.36 & - & \\
\hline $10^{*}$ & 0.06 & - & & 0.43 & - & \\
\hline $11^{*}$ & 0.40 & - & & 0.79 & - & \\
\hline $12^{*}$ & - & 1.26 & 5.4 & - & 0.78 & 1.5 \\
\hline $13^{*}$ & - & 0.98 & 4.2 & - & 0.63 & 1.2 \\
\hline $14^{*}$ & - & 2.61 & 11.2 & - & 1.07 & 2.0 \\
\hline Mean \pm SD & $0.33 \pm 0.16$ & $1.71 \pm 0.57$ & $5.7 \pm 2.9$ & $0.39 \pm 0.25$ & $0.64 \pm 0.30$ & $1.86 \pm 0.81$ \\
\hline
\end{tabular}

*supplemented with ${ }^{13} \mathrm{C}-\mathrm{Met}$

$3.2 \mathrm{~m}$ long and $1 / 8 \mathrm{in}$. in diameter. The length of the precolumn was $0.8 \mathrm{~m}$. The GC gas flow scheme and automated sampling was that of Mosier and Mack (1980) and Loftfield (1997), and peak area integration was undertaken with the software PeakSimple, version 2.66. The SD of the mean of six atmospheric air standard samples was below 1.0, 0.5 and $0.2 \%$ for $\mathrm{CO}_{2}, \mathrm{~N}_{2} \mathrm{O}$ and $\mathrm{CH}_{4}$, respectively.

\subsection{Continuous flow IRMS for the measurement of $\delta^{13} \mathrm{C}$ values of $\mathrm{CH}_{4}$}

Headspace gas from the flasks was transferred to an evacuated sample loop $(40 \mathrm{~mL})$. Interfering compounds were separated by $\mathrm{GC}$ and $\mathrm{CH}_{4}$ trapped on HayeSep D. The sample was then transferred to the IRMS system (ThermoFinnigan Delta $^{\text {plus }}$ XL, Thermo Finnigan, Bremen, Germany) via an open split. The reference gas was carbon dioxide of high purity (carbon dioxide 4.5, Messer Griesheim, Frankfurt, Germany) with a known $\delta^{13} \mathrm{C}$ value of $-23.64 \%$ (V-PDB). All $\delta^{13} \mathrm{C}$ values were normalized relative to V-PDB (Vienna Pee Dee Belemnite) using a $\mathrm{CH}_{4}$ standard. Samples were routinely analyzed three times $(n=3)$, and the average standard deviations of the GC/C/IRMS measurements were in the range of 0.1 to $0.3 \%$.

All ${ }^{13} \mathrm{C} /{ }^{12} \mathrm{C}$ isotope ratios are expressed in the conventional $\delta$ notation in per mil versus V-PDB, (\%o) using the following equation (Eq. 1):

$\delta^{13} \mathrm{C}_{\mathrm{V}-\mathrm{PDB}}=\frac{\left({ }^{13} \mathrm{C} /{ }^{12} \mathrm{C}\right)_{\text {sample }}}{\left({ }^{13} \mathrm{C} /{ }^{12} \mathrm{C}\right)_{\text {standard }}}-1$.

\subsection{Statistics}

For the evaluation of the results from experiments with $L$. angustifolia plants, we utilized the software package SPSS Version 20. In the initial experiment a paired sample $t$ test was used to compare the rates of $\mathrm{CH}_{4}$ production between consecutive "non-stressed" and "stressed" treatments on the same plants (Levene's test was 0.394 after log transformation of data). For the purpose of brevity, from this point forward this experiment will be referred to as the consecutive treatment experiment. The second experiment, in which simultaneously different samples were used to compare between non-stressed and stressed treatments, is referred to as the parallel treatment experiment. The $\mathrm{CH}_{4}$ and $\delta^{13} \mathrm{CH}_{4}$ emission ratio between stressed and non-stressed plants (Table 1) was calculated by using the mean value of the samples 9-11 as reference for the non-stressed plants.

Data from experiment 2 and differences between experiments 1 and 2 were analyzed by an independent samples $t$ test. Differences between results are given as significant $(p<0.05)$ or highly significant $(p<0.001)$.

In the case in which no significant differences occurred between the control (no stress applied or Met added) and in the treatment in which only Met was added, $\mathrm{CH}_{4}$ emission rates and $\mathrm{CH}_{4}: \mathrm{CO}_{2}$ ratios were pooled in order to calculate the mean values. 


\section{Results}

\subsection{L. angustifolia supplemented with $-\mathrm{S}-\mathrm{CH}_{3}$ positionally labeled Met and the effect of physical stress}

We investigated $\mathrm{CH}_{4}$ emissions of $L$. angustifolia supplemented with ${ }^{13} \mathrm{C}$ positionally labeled Met $\left({ }^{13} \mathrm{CH}_{3}\right.$-Met; only the methyl group $-\mathrm{S}-\mathrm{CH}_{3}$ was enriched with ${ }^{13} \mathrm{C}$ atoms). under stressed and non-stressed conditions. The incubations were carried out in total darkness in order to exclude possible light effects and to measure the gross respiration of plants. The effect of physical stress was investigated in parallel experiments in which, in each case, three different individual plants were placed under stressed and non-stressed conditions. Additionally, an experiment was performed in which $\mathrm{CH}_{4}$ emissions were first measured on intact plants, and then, after physical stress was applied to these plants, $\mathrm{CH}_{4}$ emissions were again measured.

The $\mathrm{CH}_{4}$ emission rates of non-stressed L. angustifolia plants ranged from 0.06 to $0.57 \mathrm{ng} \mathrm{CH}_{4} \mathrm{~g}^{-1} \mathrm{DW} \mathrm{h}^{-1}$, with a mean value of $0.33 \pm 0.16 \mathrm{ng} \mathrm{CH}_{4} \mathrm{~g}^{-1} \mathrm{DW} \mathrm{h}^{-1}$ (Table 1).

Physical stress enhanced $\mathrm{CH}_{4}$ emissions by a factor of 5.7 up to a mean $\mathrm{CH}_{4}$ emission rate of $1.7 \pm 0.57 \mathrm{ng} \mathrm{g}^{-1} \mathrm{~h}^{-1}$ $(n=8)$. The effect of physical stress was significant both for plants undergoing consecutive treatment (paired $t$ test with $p=0.002, n=5)$ and those in the parallel treatment experiment (independent samples $t$ test with $p=0.005$ ). The addition of Met did not affect the $\mathrm{CH}_{4}$ production of nonstressed plants (Table 1, comparison of flasks 6-8 vs. 9-11; $p=0.632, n=3)$.

L. angustifolia $(n=2)$ supplemented with ${ }^{13} \mathrm{CH}_{3}-\mathrm{Met}$ showed a strong response in the isotope signal with $\delta^{13} \mathrm{C}\left(\mathrm{CH}_{4}\right)$. After the addition of ${ }^{13} \mathrm{CH}_{3}$-Met to the roots $(n=2), \delta^{13} \mathrm{C}\left(\mathrm{CH}_{4}\right)$ values increased from -47 at time 0 to 29 and $97 \%$ after $20 \mathrm{~h}$ in non-stressed (Fig. 1d) and stressed plants (Fig. 1f), respectively, whereas in the control samples $(n=3)$ only a marginal change $( \pm 1 \%$ o $)$ was noted (Fig. 1b). Mean changes in $\Delta^{13} \mathrm{CH}_{4}$ signature were $0.39 \pm 0.16 \% \mathrm{~g}^{-1} \mathrm{~h}^{-1}$ for the non-stressed plants. After stressing, a strong response in the mixing ratio of $\mathrm{CH}_{4}$ occurred (Fig. 1), reaching a $\Delta^{13} \mathrm{CH}_{4}$ of up to $0.64 \pm 0.30 \% \mathrm{~g}^{-1} \mathrm{~h}^{-1}$ (Table 1). The ${ }^{13} \mathrm{C}$ signature increase in headspace $\mathrm{CH}_{4}$ over time (Fig. 1d, f) clearly shows that the methyl group of Met is a precursor of $\mathrm{CH}_{4}$ in plants under both non-stressed and stressed conditions.

For non-stressed and stressed plants, on average 0.008 and $0.009 \%$ of ${ }^{13} \mathrm{CH}_{3}$-Met molecules were converted daily to $\mathrm{CH}_{4}$, assuming that all ${ }^{13} \mathrm{CH}_{3}$-Met was taken up by the plant.

The ratio of $\mathrm{CH}_{4}$ emissions (5.7) and $\Delta^{13} \mathrm{CH}_{4} \mathrm{~h}^{-1} \mathrm{~g}^{-1}$ (1.9) between stressed and non-stressed plants (Table 1) indicated a higher effect of physical stress on $\mathrm{CH}_{4}$ formation than on the changes in $\delta^{13} \mathrm{C}\left(\mathrm{CH}_{4}\right)$ values.

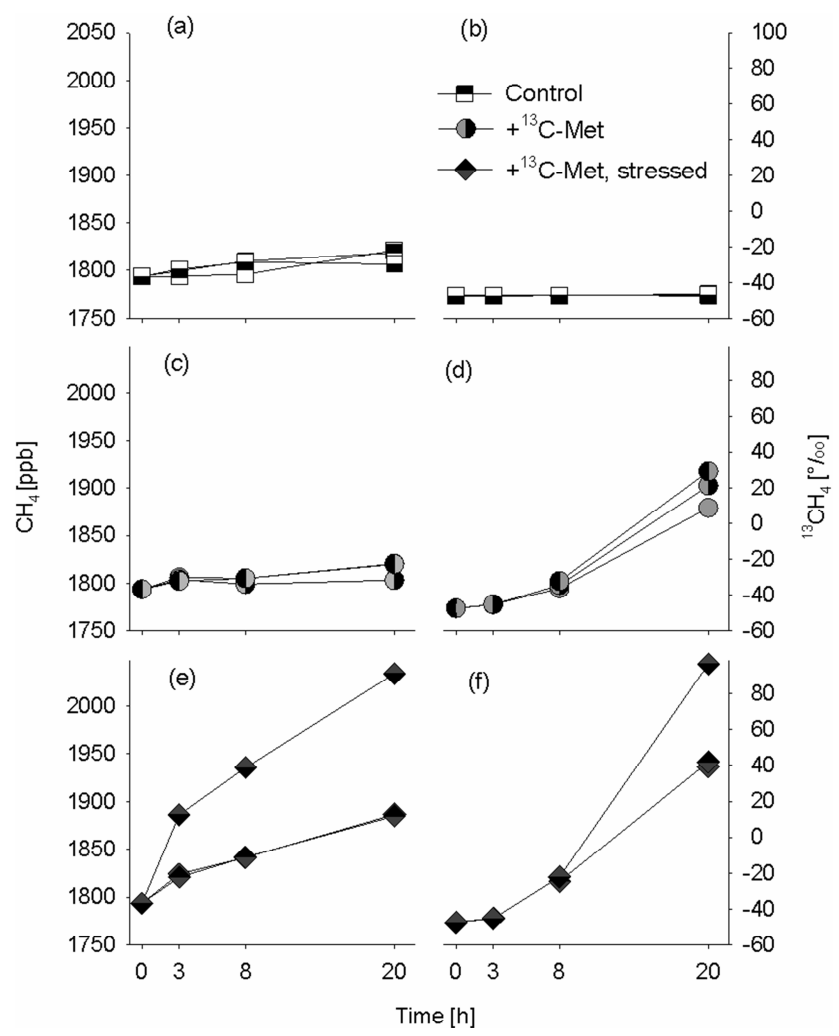

Figure 1. Mixing ratios (a, c, e) and $\delta^{13} \mathrm{C}$ values (b, d, f) of $\mathrm{CH}_{4}$ produced by L. angustifolia $(n=3)$ in the control flasks $(\mathbf{a}, \mathbf{b})$ without addition of methionine or physical stress, supplemented with ${ }^{13} \mathrm{C}$-labeled Met without physical stress $(\mathbf{c}, \mathbf{d})$ and supplemented with ${ }^{13} \mathrm{C}$-labeled Met and the application of physical stress $(\mathbf{e}, \mathbf{f})$ Different symbols mark the replicates per treatment.

\subsection{Respiration}

During the incubation of $L$. angustifolia, changes in the $\mathrm{CO}_{2}$ mixing ratio were also monitored. Since the incubation was conducted in the dark, no $\mathrm{CO}_{2}$ uptake took place and thus changes in the mixing ratio only reflect the plants' respiration. Respiration was on average $0.36 \pm 0.14$ and $0.50 \pm 0.16 \mathrm{mg} \mathrm{CO}_{2} \mathrm{~g}^{-1} \mathrm{~h}^{-1}$ for non-stressed and stressed plants, respectively.

The $\mathrm{CO}_{2}$ production by respiration reflects the metabolic activity of the plants, and to relate $\mathrm{CH}_{4}$ production to metabolic activity, we related $\mathrm{CH}_{4}$ formation to respiration by calculating the $\mathrm{CH}_{4}: \mathrm{CO}_{2}$ ratio $\left(\mathrm{mol}: \mathrm{mol} \times 10^{6}\right)$ separately for each sample. Figure 2 shows the $\mathrm{CH}_{4}$ and $\mathrm{CO}_{2}$ production rates and the respective $\mathrm{CH}_{4}: \mathrm{CO}_{2}$ ratio, which was $2.0 \pm 1.1$ for the non-stressed plants $(n=6)$ and $8.5 \pm 1.8$ for the plants to which physical stress was applied $(n=3)$. Thus, physical damage resulted in a 4-fold increase in the $\mathrm{CH}_{4}: \mathrm{CO}_{2}$ ratio $(p=0.004)$. The supplementation of plants with Met did not affect the $\mathrm{CH}_{4}$ or $\mathrm{CO}_{2}$ emission rates $(p>0.1)$. 

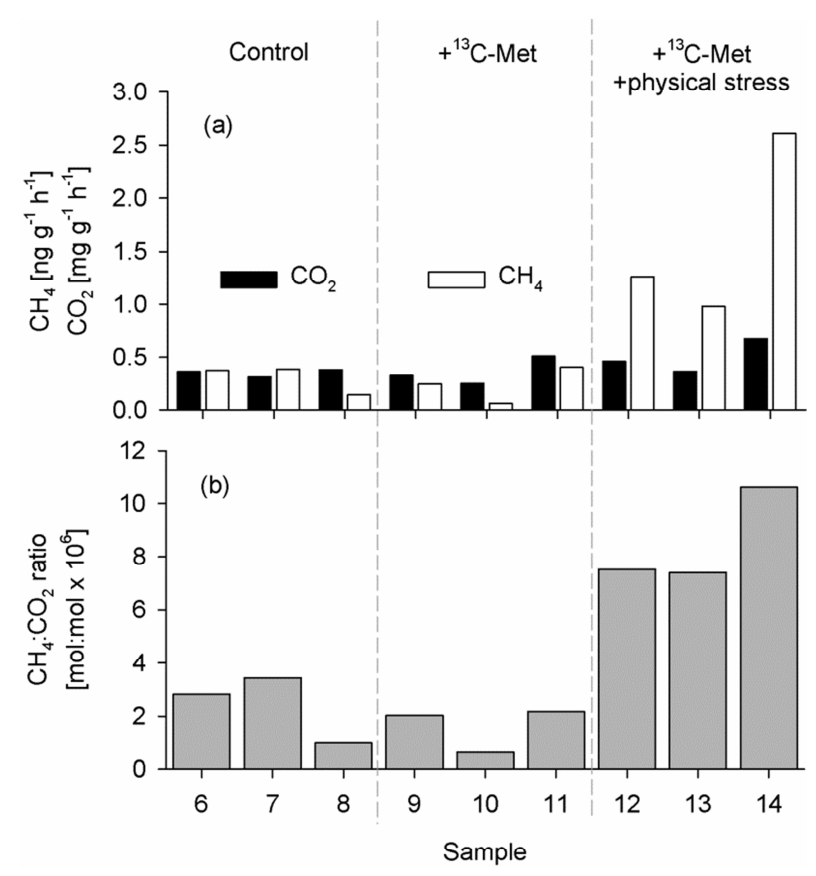

Figure 2. (a) Methane and $\mathrm{CO}_{2}$ emissions of L. angustifolia supplemented with ${ }^{13} \mathrm{C}$-labeled Met under non-stressed conditions and after application of physical stress, and (b) $\mathrm{CH}_{4}: \mathrm{CO}_{2}$ emission ratio. Control plants were not supplemented with Met or exposed to physical stress.

\section{Discussion}

\subsection{Effects of physical stress on $\mathrm{CH}_{4}$ production}

Methane emission rates of $0.33 \pm 0.16$ and $1.71 \pm 0.57 \mathrm{ng} \mathrm{g}^{-1} \mathrm{DW} \mathrm{h}^{-1}$ were observed for L. angustifolia under non-stressed and physically stressed conditions, respectively. The upper range (under physical stress) here is still considerably lower (1-2 orders of magnitude) than the range of $\mathrm{CH}_{4}$ emission rates from intact living plants (12 to $370 \mathrm{ng} \mathrm{g}^{-1} \mathrm{DW} \mathrm{h}^{-1}$ ) reported by Keppler et al. (2006) and those reported from crop species under environmental stress (Qaderi and Reid, 2009, 2011).

Without the application of physical stress the calculated emission rates were considerably lower (by a factor of 3 ), with maximum values reaching $0.57 \mathrm{ng} \mathrm{CH}_{4} \mathrm{~g}^{-1} \mathrm{DWh}^{-1}$, and are similar to those reported in previous studies employing stable carbon isotope labeling tools, (Brüggemann et al., 2009; Wishkerman et al., 2011). The very low values reported here again highlight the benefit of using stable isotope tools, as it would be very difficult to clearly monitor aerobic $\mathrm{CH}_{4}$ formation in non-stressed living plants without employing them. This might also include the sensitive optical online methods employed in several studies (Dueck et al., 2007; Beerling et al., 2008). However, these spectroscopic methods might be able to measure $\mathrm{CH}_{4}$ formation in plants under particular stress conditions.
Earlier studies (Wang et al., 2009, 2011a, b) already revealed a significant increase in $\mathrm{CH}_{4}$ emissions after physical injury and suggested reactive oxygen species (ROS) to be involved in the cleavage of methyl groups from pectin and/or lignin (Wang et al., 2011b; Keppler et al., 2008; McLeod et al., 2008; Messenger et al., 2009). Our finding of close to a 4-fold increase in $\mathrm{CH}_{4}$ emissions after the application of physical stress is within the range of the values reported by Wang et al. (2011b), where the $\mathrm{CH}_{4}$ emission rates of L. angustifolia were $0.42 \pm 0.05$ and $6.32 \pm 0.69 \mathrm{ng} \mathrm{g}^{-1} \mathrm{~h}^{-1}$ for intact leaves and after wounding, respectively. In that study, observations of $\mathrm{CH}_{4}$ emission rates of intact plants $\left(0.4 \mathrm{ng} \mathrm{g}^{-1} \mathrm{~h}^{-1}\right)$ and after wounding $\left(0.7 \mathrm{ng} \mathrm{g}^{-1} \mathrm{~h}^{-1}\right)$ for 56 plant species were reported. The discrepancy in the physical stress-induced response in $\mathrm{CH}_{4}$ emissions of L. angustifolia might be due to an exceptionally high response of this species when compared to other species tested by Wang et al. (2011b). Differences in the stress response between samples (the ratio between stressed and non-stressed plants was in the range of 3.3 to 11.2) in this study might be due to a different degree of injury during the compression of the individual leaves of each plant.

\section{2 $\mathrm{CH}_{4}: \mathrm{CO}_{2}$ ratio}

Based on the $\mathrm{CH}_{4}$ and $\mathrm{CO}_{2}$ emission rates, the calculated $\mathrm{CH}_{4}: \mathrm{CO}_{2}$ ratio $\left(\mathrm{mol}: \mathrm{mol} \times 10^{6}\right)$ of intact plants was $2.0 \pm 1.1(n=6)$, i.e. per mol $\mathrm{CO}_{2} 2.0 \mu \mathrm{mol} \mathrm{CH}_{4}$ was released by the plants.

This is close to the ratios observed for saprotrophic fungi including Pleurotus sapidus, Stereum sanguinolentum, Phanerochaete chrysosporium, in which the $\mathrm{CH}_{4}: \mathrm{CO}_{2}$ ratio was $3.5 \pm 1.92 \mathrm{~mol}: \mathrm{mol} \times 10^{6}$ or $1.15 \pm 0.70 \mathrm{ng}: \mathrm{mg}$ (Lenhart et al., 2012), and cryptogams including mosses and lichens $(n=31)$, with a ratio of $2.58 \pm 2.60 \mathrm{~mol}: \mathrm{mol} \times 10^{6}$ or $0.94 \pm 0.95 \mathrm{ng}: \mathrm{mg}$ (Lenhart et al., 2015). The $\mathrm{CH}_{4}: \mathrm{CO}_{2}$ ratio of $L$. angustifolia tends to be lower, but, as indicated by the standard deviation, this difference is probably not significant.

The physical stress-induced increase in the $\mathrm{CH}_{4}: \mathrm{CO}_{2}$ ratio (by a factor of 4 ) of up to $8.5 \pm 1.8$ was caused by a significant increase in $\mathrm{CH}_{4}$ emissions accompanied by only a small increase in respiration. The overall stress-induced increase in the respiration of $L$. angustifolia compared to non-stressed plants was $40 \%$ (n.s., $p>0.3$ ), which is similar to that observed by Wang et al. (2009), who reported a $50 \%$ increase in $\mathrm{CO}_{2}$ emissions for plants physically wounded by cutting compared to those left uncut. The $\mathrm{CH}_{4}: \mathrm{CO}_{2}$ ratio might be a useful tool to relate $\mathrm{CH}_{4}$ emissions to metabolic activity in the dark and to compare $\mathrm{CH}_{4}$ emission rates of different species obtained under different conditions. 


\subsection{Methionine as a precursor of $\mathrm{CH}_{4}$ in plants}

Based on the addition of ${ }^{13} \mathrm{CH}_{3}$-Met and stable carbon isotope measurements, it was possible to clearly monitor ${ }^{13} \mathrm{CH}_{4}$ formation in L. angustifolia. The increase in the $\delta^{13} \mathrm{CH}_{4}$ signature of $\mathrm{CH}_{4}$ released by the plants after supplementation with ${ }^{13} \mathrm{CH}_{3}$-Met (Fig. 1, Table 1) is a strong indicator that the methyl thiol group of Met is a $\mathrm{CH}_{4}$ precursor during metabolic processes. When plants were physically stressed, there was not only an increase in $\mathrm{CH}_{4}$ release but also an increase in its ${ }^{13} \mathrm{CH}_{4}$ signature (Fig. 1, Table 1).

It is important to note that our data cannot be used to conclude that methionine per se is a direct precursor of $\mathrm{CH}_{4}$ in plants. Indeed, since most methionine resides in proteins, it is much more likely to be the source of $\mathrm{CH}_{4}$ production after oxidation by ROS as suggested by Bruhn et al. (2012). These researchers based their hypothesis on the finding that dimethyl sulfoxide (DMSO) could act as a hydroxyl radical scavenger in cells and produces $\mathrm{CH}_{4}$ via a radical mechanism (Repine et al., 1981). They argued that, when the amino acid methionine is oxidized, the first oxidized product is methionine sulfoxide, the side chain of which is similar to DMSO. Therefore, methionine sulfoxide might also be a precursor of $\mathrm{CH}_{4}$ biosynthesis. The concentration of the free amino acid in normal plant tissues is $<100 \mu \mathrm{M}$ (Inaba et al., 1994), while that found in protein is $2-3$ orders of magnitude higher (Bruhn et al., 2012). Methionine residues are known to be prone to oxidation by $\mathrm{H}_{2} \mathrm{O}_{2}$ (Levine et al., 1996; Moller et al., 2007) to form methionine sulfoxide. Based on the calculations of Bruhn et al. (2012), it would only require a conversion rate and release of less than one $\mathrm{CH}_{4}$ molecule per hour for every 1000 protein methionine sulfoxide to explain a release rate of $10 \mathrm{ng} \mathrm{CH}_{4} \mathrm{~g}^{-1} \mathrm{DW} \mathrm{h}^{-1}$ by intact plant tissues. These considerations are strongly supported by findings reported in a recent chemical study (Althoff et al., 2014) which suggest that, under oxidative conditions, demethylation of sulfoxides might lead to $\mathrm{CH}_{4}$. In that study methyl groups of organosulfur compounds were shown to be efficiently converted to $\mathrm{CH}_{4}$ when using iron(II/III), hydrogen peroxide and ascorbic acid as reagents. It is thought that methyl sulfides are first oxidized to the corresponding sulfoxides and demethylation of the sulfoxide via homolytic bond cleavage leads to methyl radical formation and then to $\mathrm{CH}_{4}$.

However, in our study we focused on the identification of the precursor compound of $\mathrm{CH}_{4}$ in living plants and the location of the carbon atom within the precursor molecule. Thus, additional investigations and measurements concerning the formation of ROS, distinguishing between free methionine and that in protein, as well as the possibility of methionine residue oxidation to Met-SO will need to be undertaken.

In addition to methionine, several other organic compounds with methyl- or methoxyl groups were already identified to serve as a substrate for $\mathrm{CH}_{4}$ formation in plants (McLeod et al., 2008; Vigano et al., 2008; Bruhn et al., 2009; Keppler et al., 2008; Messenger et al., 2009). Thus, in our experiment other organic compounds besides Met, such as pectin, lignin or choline, might also serve as further methylgroup donors for $\mathrm{CH}_{4}$ formation. A detailed discussion on potential plant precursors of $\mathrm{CH}_{4}$ was recently provided by Wang et al. (2013).

\section{Conclusions and outlook}

Our study is an important step in deciphering the precursor compounds involved in $\mathrm{CH}_{4}$ biosynthesis in living plants. The employment of ${ }^{13} \mathrm{CH}_{3}$-Met clearly showed that the sulfur-bonded carbon atom of the methyl group in methionine was transferred to $\mathrm{CH}_{4}$ in L. angustifolia. Knowledge of the precursor compound and the identification of the carbon atom involved is a first step towards elucidating the pathway of its formation. An understanding of the mechanisms of $\mathrm{CH}_{4}$ formation in living plants may reveal whether the process has a more general physiological role. Further experiments in which other stress factors in combination with ${ }^{13} \mathrm{CH}_{3}$-methionine are investigated should provide further insight into the pathways involved in $\mathrm{CH}_{4}$ formation.

Although it has been argued that plants may not produce $\mathrm{CH}_{4}$ as an end product or by-product of their metabolism (Nisbet et al., 2009), our results would strongly indicate that plants do contain a mechanism for $\mathrm{CH}_{4}$ production. The stress-induced increase in $\mathrm{CH}_{4}$ emissions together with studies of sterile plants (Wishkerman et al., 2011) or cryptogamic covers supplemented with diverse inhibitors (Lenhart et al., 2015) do not support the hypothesis of a noteworthy contribution of Archaea to plant-derived $\mathrm{CH}_{4}$ formation in this study. However, we did not scan for methanogenic Archaea in the wooden parts of Lavendula plants to exclude archaealderived $\mathrm{CH}_{4}$ formation as postulated by Covey et al. (2012). Furthermore, it is considered that organosulfur compounds might play an important role in the formation of $\mathrm{CH}_{4}$ in living plants, particularly when under stress conditions.

Acknowledgements. We are grateful to John Hamilton for his thoughtful comments on an early version of this manuscript. We thank Sonja Jung, Ilka Hermes, Christoph Hann and Tamara Borrmann for assistance. This work was funded by the ESF (EURYI Award to F. Keppler) and DFG (KE 884/2-1, KE 884/8-1 and KE 884/9-1).

Edited by: E. Pendall 


\section{References}

Althoff, F., Jugold, A., and Keppler, F.: Methane formation by oxidation of ascorbic acid using iron minerals and hydrogen peroxide, Chemosphere, 80, 286-292, 2010.

Althoff, F., Benzing, K., Comba, P., McRoberts, C., Boyd, D. R., Greiner, S., and Keppler, F.: Abiotic methanogenesis from organosulfur compounds under ambient conditions, Nature Communications, 5, 4205, doi:10.1038/ncomms5205, 2014.

Beerling, D. J., Gardiner, T., Leggett, G., Mcleod, A., and Quick, W.: Missing methane emissions from leaves of terrestrial plants, Glob. Change Biol., 14, 1821-1826, 2008.

Bloom, A. A., Lee-Taylor, J., Madronich, S., Messenger, D. J., Palmer, P. I., Reay, D. S., and McLeod, A. R.: Global methane emission estimates from ultraviolet irradiation of terrestrial plant foliage, New Phytol., 187, 417-425, 2010.

Brüggemann, N., Meier, R., Steigner, D., Zimmer, I., Louis, S., and Schnitzler, J. P.: Nonmicrobial aerobic methane emission from poplar shoot cultures under low-light conditions, New Phytol., 182, 912-918, doi:10.1111/j.1469-8137.2009.02797.x, 2009.

Bruhn, D., Mikkelsen, T. N., Øbro, J., Willats, W. G. T., and Ambus, P.: Effects of temperature, ultraviolet radiation and pectin methyl esterase on aerobic methane release from plant material, Plant Biol., 11, 43-48, doi:10.1111/j.1438-8677.2009.00202.x, 2009.

Bruhn, D., Møller, I. M., Mikkelsen, T. N., and Ambus, P.: Terrestrial plant methane production and emission, Physiol. Plantarum, 144, 201-209, doi:10.1111/j.1399-3054.2011.01551.x, 2012.

Bruhn, D., Mikkelsen, T. N., Rolsted, M., Egsgaard, H., and Ambus, P.: Leaf surface wax is a source of plant methane formation under UV radiation and in the presence of oxygen, Plant Biol., 16, 512516, 2014

Covey, K. R., Wood, S. A., Warren II, R. J., Lee, X., and Bradford, M. A.: Elevated methane concentrations in trees of an upland forest, Geophys. Res. Lett., 39, L15705, doi:10.1029/2012g1052361, 2012.

Dueck, T. A., de Visser, R., Poorter, H., Persijn, S., Gorissen, A., de Visser, W., Schapendonk, A., Verhagen, J., Snel, J., Harren, F. J. M., Ngai, A. K. Y., Verstappen, F., Bouwmeester, H., Voesenek, L. A. C. J., and van der Werf, A.: No evidence for substantial aerobic methane emission by terrestrial plants: a ${ }^{13} \mathrm{C}$ labelling approach, New Phytol., 02103, doi:10.1111/j.14698137.2007.02103.x, 2007.

Evans, J. R.: Resolving methane fluxes, New Phytol., 175, 1-4, doi:10.1111/j.1469-8137.2007.02114.x, 2007.

Inaba, K., Fujiwara, T., Hayashi, H., Chino, M., Komeda, Y., and Naito, S.: Isolation of an Arabidopsis thaliana Mutant, mto1, That Overaccumulates Soluble Methionine (Temporal and Spatial Patterns of Soluble Methionine Accumulation), Plant Physiol., 105, 1465-1465, 1994.

Kammann, C., Hepp, S., Lenhart, K., and Müller, C.: Stimulation of methane consumption by endogenous $\mathrm{CH}_{4}$ production in aerobic grassland soil, Soil Biol. Biochem., 41, 622-629, 2009.

Kammann, C., Ratering, S., Eckhard, C., and Müller, C.: Biochar and hydrochar effects on greenhouse gas (carbon dioxide, nitrous oxide, and methane) fluxes from soils, J. Environ.Qual., 41, 1052-1066, 2012.

Keppler, F., Hamilton, J. T. G., Braß, M., and Röckmann, T.: Methane emissions from terrestrial plants under aerobic conditions, Nature, 439, 187-191, 2006.
Keppler, F., Hamilton, J. T. G., McRoberts, W. C., Vigano, I., Braß, M., and Röckmann, T.: Methoxyl groups of plant pectin as a precursor of atmospheric methane: evidence fom deuterium labelling studies, New Phytol., 02411, doi:10.1111/j.14698137.2008.02411.x, 2008.

Keppler, F., Boros, M., Frankenberg, C., Lelieveld, J., McLeod, A., Pirttilä, A. M., Röckmann, T., and Schnitzler, J.: Methane formation in aerobic environments, Environ. Chem., 6, 459-465, 2009.

Kirschbaum, M. U. F. and Walcroft, A.: No detectable aerobic methane efflux from plant material, nor from adsorption/desorption processes, Biogeosciences, 5, 1551-1558, doi:10.5194/bg-5-1551-2008, 2008.

Lenhart, K., Bunge, M., Ratering, S., Neu, T. R., Schüttmann, I., Greule, M., Kammann, C., Schnell, S., Müller, C., Zorn, H., and Keppler, F.: Evidence for methane production by saprotrophic fungi, Nat. Commun., 3, 1046, doi:10.1038/ncomms2049, 2012.

Lenhart, K., Weber, B., Elbert, W., Steinkamp, J., Müller, C., Clough, T., Crutzen, P., Pöschl, U., and Keppler, F.: Nitrous oxide and methane emissions of cryptogamic covers on ground and plant surfaces, submitted.

Levine, R. L., Mosoni, L., Berlett, B. S., and Stadtman, E. R.: Methionine residues as endogenous antioxidants in proteins, P. Natl. Acad. Sci. USA, 93, 15036-15040, 1996.

Loftfield, N.: Automated gas chromatographic system for rapid analysis of the atmospheric trace gases methane, carbon dioxide, and nitrous oxide, J. Environ. Qual., 26, 560-564, 1997.

McLeod, A. R., Fry, S. C., Loake, G. J., Messenger, D. J., Reay, D. S., Smith, K. A., and Yun, B. W.: Ultraviolet radiation drives methane emissions from terrestrial plant pectins, New Phytol., 180, 124-132, 2008.

Messenger, D. J., McLeod, A. R., and Fry, S. C.: The role of ultraviolet radiation, photosensitizers, reactive oxygen species and ester groups in mechanisms of methane formation from pectin, Plant Cell Environ., 32, 1-9, doi:10.1111/j.1365-3040.2008.01892.x, 2009.

Moller, I. M., Jensen, P. E., and Hansson, A.: Oxidative modifications to cellular components in plants, Annu. Rev. Plant Biol., 58, 459-481, 2007.

Mosier, A. R. and Mack, L.: Gas-chromatographic system for precise, rapid analysis of nitrous oxide, Soil Sci. Soc. Am. J., 44, 1121-1123, 1980.

Nisbet, R. E. R., Fisher, R., Nimmo, R. H., Bendall, D. S., Crill, P. M., Gallego-Sala, A. V., Hornibrook, E. R. C., López-Juez, E., Lowry, D., Nisbet, P. B. R., Shuckburgh, E. F., Sriskantharajah, S., Howe, C. J., and Nisbet, E. G.: Emission of methane from plants, P. Roy. Soc. B Biol. Sci., 276, 1347-1354, doi:10.1098/rspb.2008.1731, 2009

Qaderi, M. M. and Reid, D. M.: Methane emissions from six crop species exposed to three components of global climate change: temperature, ultraviolet-B radiation and water stress, Physiol. Plantarum, 137, 139-147, 2009.

Qaderi, M. M. and Reid, D. M.: Stressed crops emit more methane despite the mitigating effects of elevated carbon dioxide, Funct Plant Biol., 38, 97-105, 2011.

Repine, J. E., Fox, R. B., and Berger, E. M.: Dimethyl sulfoxide inhibits killing of Staphylococcus aureus by polymorphonuclear leukocytes, Infect. Immun., 31, 510-513, 1981.

Vigano, I., van Weelden, H., Holzinger, R., Keppler, F., McLeod, A., and Röckmann, T.: Effect of UV radiation and temperature on the 
emission of methane from plant biomass and structural components, Biogeosciences, 5, 937-947, doi:10.5194/bg-5-937-2008, 2008.

Wang, Z.-P., Han, X.-G., Wang, G. G., Song, Y., and Gulledge, J.: Aerobic Methane Emission from Plants in the Inner Mongolia Steppe, Environ. Sci. Technol., 42, 62-68, 2008.

Wang, Z.-P., Gulledge, J., Zheng, J.-Q., Liu, W., Li, L.-H., and Han, X.-G.: Physical injury stimulates aerobic methane emissions from terrestrial plants, Biogeosciences, 6, 615-621, doi:10.5194/bg-6-615-2009, 2009.

Wang, Z.-P., Xie, Z.-Q., Zhang, B.-C., Hou, L.-Y., Zhou, Y.-H., Li, L.-H., and Han, X.-G.: Aerobic and Anaerobic Nonmicrobial Methane Emissions from Plant Material, Environ. Sci. Technol., 45, 9531-9537, doi:10.1021/es2020132, 2011a.
Wang, Z.-P., Keppler, F., Greule, M., and Hamilton, J. T. G.: Nonmicrobial methane emissions from fresh leaves: Effects of physical wounding and anoxia, Atmos. Environ., 45, 4915-4921, $2011 b$.

Wang, Z.-P., Chang, S. X., Chen, H., and Han, X.-G.: Widespread non-microbial methane production by organic compounds and the impact of environmental stresses, Earth-Sci. Rev., 127, 193202, 2013.

Wishkerman, A., Greiner, S., Ghyczy, M., Boros, M., Rausch, T., Lenhart, K., and Keppler, F.: Enhanced formation of methane in plant cell cultures by inhibition of cytochrome c oxidase, Plant Cell Environ., 34, 457-464, doi:10.1111/j.13653040.2010.02255.x, 2011.

Zhang, X., Lee, X., Griffis, T., Baker, J., Erickson, M., Hu, N., and Xiao, W.: The influence of plants on atmospheric methane in an agriculture-dominated landscape, Int. J. Biometeorol., 58, 819833, 2014. 